\title{
ÁGUA: O PRINCÍPIO DA HIDRODIGNIDADE HUMANA X A NECESSIDADE DO DESENVOLVIMENTO ECONÔMICO
}

\author{
Raquel Rossan Christino Gitahy ${ }^{1}$, Susy dos Santos Pereira ${ }^{2}$ \\ ${ }^{1}$ Docente do curso de Direito e do Programa de Mestrado em Educação da UNOESTE. Docente do curso de Direito e \\ Pedagogia da Universidade Estadual do Mato Grosso do Sul. ${ }^{2}$ Bacharel em Direito pela Universidade Estadual de Mato \\ Grosso do Sul.
}

\section{RESUMO}

O trabalho se propõe analisar a importância da água, ora tratada como recurso, ora tratada como bem inatingível e a sua real competência de domínio no caso dos poços artesianos no Município de Paranaíba, MS. Para a recolha de dados utilizou-se a entrevista com o órgão de Vigilância Sanitária do município, cuja intenção foi diagnosticar como é direcionada a fiscalização do uso da água em face poços artesianos de uso doméstico. Notou-se a importância de se existir leis mais eficazes que protejam as águas subterrâneas, e nesse sentido, aos famosos aquíferos, visando preservar o seu uso racional; considerou-se a necessidade dos entes públicos tutelarem as águas subterrâneas. Concluiu-se que a água é sim o bem de todos, mas deve ser cultivada por toda sociedade, num movimento uníssono, alcançando o seu verdadeiro equilíbrio às futuras gerações. Palavras - chave: poços artesianos. água. hidrodignidade. água subterrânea.

\section{INTRODUÇÃO}

Atualmente o nosso planeta é cercado de $3 / 4$ de água, que podíamos até acertadamente chamá-lo de planeta água. Dentre estas estimativas possuímos ainda um percentual de $3 \%$ de água doce, notadamente, $77 \%$ correspondem às geleiras, e $22 \%$ às águas subterrâneas, ficando somente $1 \%$ desta estimativa disponível para uso do homem. (BARLOW, 2011).

Nesse viés, o seu mau uso, como bem de despejo, desencadeou sua poluição indesejada, contribuindo e muito para seu carecimento.

Deste modo, acredita-se no direito, e em todo seu potencial transformador, na medida em que se visa dar maior efetividade às garantias fundamentais, e exaltar o princípio máximo constitucional, o da dignidade humana, no contexto o qual se insere, exalta-se o da hidrodignidade. Entendendo ser a água como recurso responsável pelo equilíbrio ambiental, e um elemento que visa à sobrevida, cumpre nos também esboçar sobre a importância de sua acessibilidade, devendo esta ser gratuita e com qualidade.

Fica imprescindível sensibilizar as pessoas pelo uso racional, devendo-se sempre assegurar a disponibilidade prometida às futuras gerações (art. 225 da Constituição Federal de 1988), tratase de evocar a água como bem da humanidade. Pois, além da qualidade deste recurso, o trabalho 
se preocupa incisivamente com o volume de sua quantidade que se extrai dos poços artesianos domiciliares, sendo essencial analisar o regime ao qual ela está tutelada.

Cabendo observar quais instrumentos legais que gerem estas águas, uma vez que o seu uso irracional ocasionará certamente o precoce esgotamento do bem, acarretando insuficientemente sua recomposição natural.

Na concepção de Limongi (1977, p.86-88 apud POMPEU, 2010, p. 43): “O direito de águas pode ser conceituado como conjunto de princípios e normas jurídicas que disciplinam o domínio, uso, aproveitamento, a conservação e preservação das águas, assim como a defesas contra suas danosas consequências". Observa-se um lado antropocêntrico, nota-se que a natureza só é preservada porque esta servirá futuramente ao proveito do homem.

Nesse tal interesse,

[...] a água vai se constituir numa estratégia de negócios neste século. $A$ conta de água, possivelmente na próxima geração, vai estar bem maior do que a de luz. Em alguns países, o custo da água já supera o do petróleo. Algumas empresas estão convencidas de que, num futuro próximo, quem detiver o controle da água do planeta vai ditar as regras do produto. (PEIXOTO FILHO; BONDAROVSKY, 2000).

A ideia então que se prospera seria de um típico ouro azul? Crê-se que água é um patrimônio global, um bem essencial à sadia qualidade de vida, e não pode se condicionar em mera mercadoria como uma afronta aos direitos humanos, uma vez que, o próprio direito econômico compõe os direitos humanos. (CHRISTOFIDIS, 2003).

Em nosso entendimento, comercializar um recurso vital para a sobrevivência, visando ao lucro, assemelha-se à prática de crime contra a humanidade. Isso faz pressupor que aquele cidadão que não tem condições para pagar pela compra de água de qualidade terá que beber água ruim e até poluída prejudicando sua saúde e pondo em risco sua própria vida. Se o direito à vida com dignidade é um preceito fundamental constitucionalmente previsto, a água (como recurso vital para a manutenção da vida), consequentemente, também é um preceito fundamental. (MACHADO, 2011, p. 356).

É preciso também entender que, ao atribuir a água um recurso indispensável à dignidade humana, não a coloca totalmente fora da esfera mercadológica, implica enquadrá-la dentro de um novo entendimento de ética: a social de atuação. Justificando-se aí discutir a sua caracterização jurídica, pois devido seu domínio ser constitucionalmente tutelado, nos convém investigar se a 
água é um bem ou um recurso, já que seu uso está sujeito a ser cobrado à luz do desenvolvimento econômico.

\section{OBJETIVO}

O intuito desse estudo foi analisar a competência de domínio do bem água, a partir da existência de poços artesianos no Município de Paranaíba - MS, ressaltando-se consequentemente a dimensão do seu uso por particulares e sua relação com o direito ambiental contemplando os princípios fundamentais para sua real proteção.

\section{METODOLOGIA}

Visou-se identificar como era realizada a extração de água dos poços artesianos no município de Paranaíba, MS mediante entrevista a funcionária responsável do órgão de vigilância do município, cuja intenção era averiguar se esta captação seguia os preceitos jurídico-ambientais adequados, uma vez que, o Município obtém inúmeros poços particulares, tanto de asilo doméstico como também em vários órgãos estatais e particularizados, advindo com isso a real necessidade de se verificar a presença do licenciamento ambiental na abertura desses poços, como também a real necessidade da outorga do poder público.

\section{RESULTADOS}

Como titular de outorga caberia ao Estado esta fiscalização conforme a lei pátria nos direciona no seu art.26, inciso I, logo, o domínio sobre os poços artesianos excluía os Municípios. Todavia isso não quer dizer que os Municípios não teriam a competência de suplementar e assim fiscalizar a utilização da água.

Diante desta observância buscou-se a levantar as leis que regiam sobre a temática, e nesta perspectiva, se dispôs da Resolução SEMAC n. 08, de 06 de julho de 2009, criada pelo Instituto do Meio Ambiente de Mato Grosso do Sul - IMASUL, esta disciplina o licenciamento ambiental de poços tubulares.

Entendendo ser também dever do Município de suplementar esta fiscalização, buscou-se deste modo também colher informações no órgão da Vigilância Sanitária de Paranaíba, e nesta oportunidade foi entrevistada a funcionária responsável sobre o tratamento das águas em relação à saúde no Município, cujo roteiro se expõe abaixo: 


\section{Como é realizado o licenciamento de poços?}

Segundo a responsável, as águas dos poços artesianos são alternativas para o abastecimento de água, considerada uma via mais barata para o usuário defronte inúmeros aumentos da taxa de água; pois segundo ela, a SANESUL ${ }^{1}$ não suportaria abastecer toda população, todavia tal extração foge do aval da Vigilância Municipal, nós só fiscalizamos as águas dos poços das instituições dentro do Sistema Alternativo Coletivo, como os dois hospitais do município.

\section{Existe um controle baseado na quantidade de água extraída?}

Como não somos responsáveis não dá para saber, pois cada pessoa cuida de seu poço.

\section{Como é realizado o licenciamento de poços?}

Na verdade, conforme a entrevistada, todos os poços aqui não têm licenciamento, são todos irregulares, até mesmo o da SANESUL que não tem a autorização devida para a captação de água.

\section{DISCUSSÃO}

Quanto ao regimento da água subterrânea no município, este uso pelos particulares não deveria, na verdade, suprir a necessidade como uma forma de reserva, no âmbito emergencial? Nesta perspectiva, é nítido enfatizar primeiramente que se faz necessário existir uma análise mais profunda dos aquíferos ${ }^{2}$, fator esse preponderante para a sua preservação.

A área urbana de Paranaíba utiliza os poços como bem livre, visando seu abastecimento doméstico. Atenta-se que a sua extração pode ser excessiva não observando os padrões ambientais, uma vez que esta captação desmedida poderá sim acarretar sérios problemas relacionados à saúde pública no município.

Nesse âmbito, os particulares colaboram consideravelmente com escoamento dos chamados aquíferos e contribuem e muito para sua total destruição, as pessoas acreditam que uma inocente perfuração de um poço artesiano não é tão relevante que eleve a degradação do meio ambiente. Constata que não há na verdade no Município um acompanhamento técnico e

\footnotetext{
${ }^{1}$ Empresa de Saneamento do Estado de Mato Grosso do Sul.

${ }^{2}$ As águas subterrâneas ficam localizadas no subsolo contidas em aquíferos, camadas capazes de fornecer quantidades significativas de águas. A intensificação da extração das águas subterrâneas desencadeou a abertura de inúmeros poços artesianos, estes criados muitas vezes de maneira desordenada, e sob nenhum controle. (GRANZIERA, 2011).
} 
estudo da sua potabilidade e nem mesmo um atlas hidrológico detalhado sobre o bem. Diante dessa situação,

[...] as perfurações desordenadas deverão ocasionar um nível elevado de rebaixamento do lençol freático, diminuindo a cada dia o nível da água, e se poluída estas águas demorarão anos para voltar o estado de origem. [...] quando uma obra de captação das águas subterrâneas - poço escavado (cacimbão) ou tubular profundo, galeria, túnel - é construída sem atender características técnicas mínimas necessárias de uso e proteção, poderá se transformar num foco de contaminação do solo-subsolo e águas subterrâneas. (REBOUÇAS, 2002, p.123).

Não existe também um estudo sobre a certeza do impacto ambiental, como ressalta Hirata: "Os estudos de deteç̧ão da contaminação de aquíferos são ainda limitados e o conhecimento real da extensão do problema é praticamente inexistente." (2003, p. 785).

Quanto à qualidade das suas águas extraídas dos poços, cabe a cada particular realizar exame desta no Departamento da SANESUL do município, nesse revés nota-se que a partir do momento que o particular abre mão do tratamento geral fornecido pela esfera pública, fica-se mais exposto às doenças oriundas da água sem o seu devido tratamento adequado. Muitas pessoas acreditam que um simples exame atestando a ausência de coliformes na água é o suficiente para certificar a qualidade do poço, mas a qualidade do recurso não se reduz a isso.

Observa-se também que os indivíduos que possuem os poços no município não pagam o uso do saneamento básico coletivo. No município existe o abastecimento de água fornecido pelo poder público municipal, ora, há que se questionar então: este ato de não pagamento dos particulares não incidiria em enriquecimento ilícito ao particular?

Entendo ser a cobrança pelo uso, como uma forma de repassar para o usuário o seu real valor; apresenta-se aqui uma outra incongruência: como pagar pelo uso se é um recurso comum de todos; não seria um enriquecimento também do poder público? Ora "[...] a população estaria pagando por um bem que já é dela". (AZEVEDO, 2012). Para Graf, (2002, p. 69) não há que se falar em pagamento pelo bem de fato: "[...] provavelmente a maioria das pessoas desconheça que 0 valor ao fim de cada mês à companhia de saneamento refere-se ao tratamento à distribuição da água e a coleta de esgoto, em não ao uso do líquido em si, que ainda é de graça".

Para Milaré (2001) e Machado (2011), a contribuição financeira pelo uso visará evitar danos pela captação da água, seria incentivar o uso racional e sustentável do recurso, isto é, ela será paga antes mesmo que aconteça o dano ambiental, exalta-se aqui o princípio do usuáriopagador e do poluidor-pagador. Granziera (2000, p. 73) direciona o entendimento "conforme o 
principio poluidor-pagador se todos têm direito a um ambiente limpo, deve o poluidor pagar pelo dano que provocou. Segundo o principio usuário-pagador, paga-se pela utilização da água, em detrimentos dos demais".

Nesse sentido, cabe ao poder público controlar o uso dos particulares que extraem a água como bem livre, pois a gestão efetiva assegurará a quantidade e qualidade, não se tratando neste instituto da alienação sobre a água. Mas o que pode-se compreender de antemão é que o fato dos particulares não pagarem pelo uso da água dos seus poços traz aos cidadãos do município uma grande sobrecarga, pois uma parte suporta o ônus total de maneira desproporcional.

\section{CONCLUSÃO}

Por meio da pesquisa não foi possível catalogar quantos poços particulares há no Município de Paranaíba, pois estes poços particulares não são mensurados e nem submetem à fiscalização e logo não possuem assegurado seu licenciamento ambiental. É nítido que apropriação/privatização da água ensejam nos indivíduos também os devidos cuidados com a manutenção e sobrevida do recurso ambiental. Em contrapartida, entende-se também que a água deveria ser um bem público distante de sofrer quaisquer tipos de apropriação por parte dos particulares, um direito indisponível, e ser compreendia como recurso vital.

Entende-se também que a Constituição é um Estatuto de uma Sociedade, a lei máxima de um Estado, e se todos a observassem e cumprissem seus ideais adequadamente logicamente não dependeríamos de inúmeras leis ordinárias, pois, todas as leis nasceram dela, logo não precisaria se manter por outros instrumentos jurídicos. Cumpre ainda observar que a captação de água destes poços é um ato tentador ao princípio da prevenção, pois é potencialmente um ato poluidor, por isso que se faz necessária a existência de maneira eficaz do licenciamento ambiental a estes usos domésticos. O princípio em si é uma medida cautelar e sua aplicação se dá por meio do controle da administração pública, pela outorga do bem.

Quanto à competência, é sim bem comum de todos; isto institui aos entes federados a forma concorrente, cabendo especialmente aos Municípios exercerem essa fiscalização de forma suplementar. O que se observou em Paranaíba é que qualquer um pode perfurar um poço na sua propriedade sem nenhum pedido de licenciamento e nem de outorga, não ficando submisso a nenhum controle nem do ente federal, estadual e nem mesmo do município. 
Falta vontade, na maioria das vezes, para os órgãos públicos, visto que, a água deveria ser entendida como um recurso intangível, devendo ser protegida não somente pelos entes federados como também por nós.

A água é indiscutivelmente um patrimônio nacional, cabendo ao povo como titular deste poder conhecer melhor os limites das águas subterrâneas, pois é nisso que justifica a prática de sua outorga. Observada sua importância no equilíbrio ambiental, fica imprescindível preservar o uso do bem, seria um gerenciamento conjunto, visando alcançar as futuras gerações, pois o tempo que se tem para se recompor esses aquíferos é extremamente demorado, pois a sua capacidade renovadora é de dezenas a centenas de anos.

O fato é que a natureza realmente aclama ajuda, e o que hoje se vê é que ela fica à mercê de si mesma.

\section{REFERÊNCIAS}

ADEDE Y CASTRO, João Marcos. Água: um direito humano fundamental. Porto Alegre: Núria Fabris Editora, 2008.

AZEVEDO, Tatianna Rangel Mello de. Natureza e aspectos jurídicos da cobrança do uso da água e sua aplicabilidade prática. Jus Navigandi, Teresina, ano 17, n. 3228, 3maio 2012. Disponível em: <http://jus.com.br/revista/texto/21663>. Acesso em: 6 out. 2012.

BARLOW, Maude. Água, pacto azul: a crise global da água e a batalha pelo controle da a'gua potável. São Paulo: M. Books do Brasil Editora Ltda, 2009.

CASARIN, Fatima; SANTOS, Monica dos. Água: o ouro azul usos e abusos dos recursos hídricos. Rio de Janeiro: Garamond, 2011.

CHRISTOFIDIS, Demetrios. Água, ética, segurança alimentar e sustentabilidade ambiental. Bahia Análise \& Dados. Salvador, 2003, v. 13, n. especial, p. 371-382.

GRAF, Ana Cláudia Bento. A tutela dos Estados sobre as águas. In: FREITAS, Vladimir Passos de (Coord.). Águas: aspectos jurídicos e ambientais. 2. ed. Curitiba: Juruá, 2002.

GRANZIERA, Maria Luiza Machado. Direito ambiental. 2. ed. São Paulo: Atlas, 2011.

. A cobrança pelo uso da água. RCEJ, Brasília, n. 12, p.71-74, set. /dez, 2000.

HIRATA, R. Gestão de recursos hídricos subterrâneos. In: CONGRESSO INTERNACIONAL DE DIREITO AMBIENTAL. BENJAMIN, A. H. (Org.). Direito, água e vida. São Paulo: Imprensa Oficial, 2003, v.1, p.785-796.

LEITE, Paulo Roberto Saraiva da Costa Água, bem mais precioso do milênio. R. CEJ, Brasília, n. 12, p. 05-07, set./dez. 2000. 
MACHADO, Roberto Ferreira. Água um direito fundamental. Revista Direito Ambiental e sociedade, v. 1, n. 1, p. 343-366, jan./jun. 2011.

MILARÉ, Édis. Direito ambiente: doutrina, prática, jurisprudência, glossário. 2. ed. São Paulo: Revista dos Tribunais, 2001.

PEIXOTO FILHO; Aser Cortines; BONDAROVSKY, Sandra Helena. Água, bem econômico e de domínio público. R. CEJ, Brasília, n. 12, p. 13-16, set./dez. 2000.

POMPEU, Cid Tomanik. Direito de águas no Brasil. 2. ed. São Paulo: Revista dos Tribunais, 2010

REBOUÇAS, Aldo da Cunha; BRAGA, Benedito; TUNDISI, José Calizia (Org.). Águas doces no Brasil: capital ecológico, uso e conservação. (lei de proteção de mananciais. 2. ed. São Paulo: Escrituras Editora, 2002. 